seen would be represented by $\mathrm{I}$; and therefore from these so-called "frequencies" we got a good iclea of the number of times we might expect to see any of these disturbance-lines, when anything was going on in the sun.

It was this kind of work which made Tennyson write those very beautiful lines:

$$
\begin{aligned}
& \text { "Science reaches forth her arms } \\
& \text { To feel from world to world" }
\end{aligned}
$$

And then he added:

$$
\text { " and charms }
$$

Her secret from the latest moon."

I mention this because Tennyson, whose mind was saturated with astronomy, had already grasped the fact that what had already been done was a small matter compared with what the spectroscope could do ; and now the prophecy is already fulfilled, for by means of the spectroscopic examination of the light from the stars we can tell that some of them are double stars, that is to say, in poetic language, stars with attendant moons. Although we can thus charm the secret from each moon by means of the spectroscope, to see the moon it would require a telescope not 80 feet long, but with an objectglass 80 feet in diameter, because the closer two stars are together the greater must be the diameter of the objectglass, independently of its focal-length and magnifying power.

(To be continuced.)

\section{THE CAMBRIDGE NATURAL HISTORY.'}

$\mathrm{T}^{\mathrm{H}}$ $\mathrm{HE}$ second volume of this series (vol. v.) to make its appearance is devoted, with the exception of articles on the Prototracheata (pp. 3-26) and Myriapoda (pp. 28-8o), to the Insecta, which will occupy also the whole of vol. vi.

Mr. Sedgwick gives a concise account of Peripatus, which, being derived mainly from his own well-known papers, does not call for extended notice ; the descriptions of anatomy and development are written in a somewhat technical style, but are not over-elaborated. If it were thought necessary to reprint an easily-accessible list of the known and doubtful species, it should certainly have been revised. No records are noted since $1888 ; P$. juliformis is given as a doubtful species, whereas at most it is incompletely characterised, and $P$. trinidadensis actually figures as "n. sp." A map, serving as frontispiece, shows the distribution; but the records from Peru and Chili seem scarcely to justify the inclusion of so much of the arid western littoral of South America.

Myriapoda are not a fascinating subject, but Mr. Sinclair's article, though slight and somewhat wanting in style, gives many particulars of interest about them. The author is clearly a morphologist rather than a systematist, and has made a serious mistake in employing a classification so antiquated as that of Koch, who knew little of extra-European forms, and whose characters, if rightly transcribed, are far from accurate. Mr. Sinclair prefers to disregard the work of systematists who have dealt with separate families only; but a system by Bollman of the whole class (or classes, according to some specialists), published in 1893 in Bulletin xlvi. of the United States National Museum, has been overlooked. In the section on development no mention is made of the reversal of the embryo referred to on p. 216 of the work. This was a matter for the editors, as is indeed the whole subject of embryology. The details of early embryonic development are so similar, that there is a risk of useless repetition and of insufficient stress on points of difference unless some co-operation is instituted among contributors. The

1 "Peripatus, Myriapods, Insects." By A. Sedgwick, F. G. Sinclair, and D. Sharp. Pp. xii t- 584. (London: Macmillan and Co., r895.) NO. I 37 I, VOL. 5.3] figures of species are copied from Koch's "Die Myriapoden," and, though the fact is not stated, that of Cermatia variegata was drawn from an example which had lost six pairs of legs!

In no branch of zoology has the influence of modern morphological and biological research been of slower growth than in entomology; the subject is so complex, so dominated by taxonomy and an unwieldy literature, that few entomologists have the energy to leave their immediate field of study in order to gain any general knowledge of the natural history of insects. For this the responsibility rests largely with the authors of the many text-books on entomology, who for the most part have been content to follow an antiquated method, basing their work on a substructure of classification, and ignoring families of the highest interest from all points of view except those of the collector and systematist, in order to fill their pages with a tedious procession of names and useless details.

For many years there has appeared no such valuable or original work on insects as this of Dr. Sharp promises to be, when completed. The author has rid himself of the chains of the systematist, and has endeavoured, in

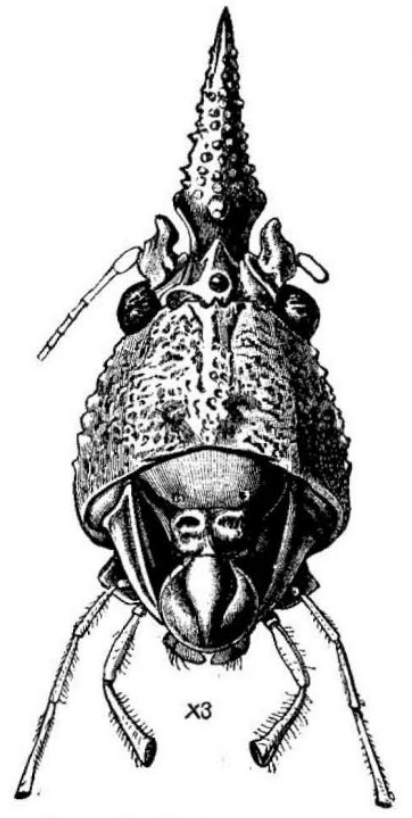

Fic. x.-Front of headrof Copiophora cornuta, female. Demerara.

the most thorough and catholic spirit, to give a just view of the many points of interest, whether in structure, development or habits, which attach to this, the richest class of the animal kingdom.

In such a task, one does not look for novelty in facts or theories, though there is ample evidence of independent thought and investigation. It is in the selection and treatment of subjects that Dr. Sharp's originality is shown, and in these the book stands absolutely alone. It is a real and new pleasure to read a work of so broad a scope, in which so much is entirely unknown except to the closest students of recent literature, in which families such as Thysanura, Hemimerida, Embiidce, or Termitida are adequately treated, and where due regard is paid to the writings of students such as Brauer, Grassi, or Cholodkowsky.

Though familiar insects are by no means neglected, and much that is interesting and new is said even about the earwig and cockroach, the number of strange and rare forms discussed is quite extraordinary. No one knows the literature of the subject better than the author, 
who has ransacked it in a way that it would have been hopeless to attempt without the preparation gained by many years' work in connection with the Zoological Recor.

His style is graphic and pleasant and, even when he is most erudite, he is never dry. Nevertheless, the book will appeal with more force to the expert than to the beginner. The definitions are often vague, notably in the chapter on external structure. This arises less from any fault in the author's method than from a reluctance to give definitions which do not embrace all known variations from a common type. To those who can read between the lines this vagueness presents no difficulty, but we suspect that the general reader will fail sometimes to get a clear conception of the subject. The insufficiency of our present knowledge is a favourite and over-emphasised text of the author, who does not conceal his dislike both to generalisation and the acceptance of morphological axioms. Though he rarely expresses his opinion, even on matters where it would be most welcome, in a remarkable footnote (p. $9 \mathrm{I})$ he suggests that the wings, equally with the legs, are "appendages." He might be thought to protest against the limitation of the term to a single homologous series, but his remarks on the possibly duplex origin of the thoracic somites tend to negative this view. That there can be any homology between the

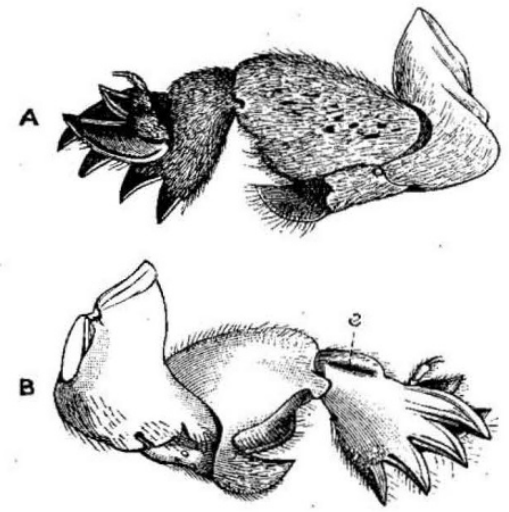

Fig. 2.-Front leg of the mole-cricket. A, outer ; $\mathrm{B}$, inner aspect ; $e$, ear-slit.

legs and wings is a dangerous suggestion to hint at in a work not intended solely for critical readers.

Where so much is novel, it is impossible, within the limits of a notice, to touch on even a small part of the subjects dealt with in the work: the development of the antennæ in Forficulida, the mimetism of Mantida, the economy of the Termites, the insects of the coal-measures, the formation of galls, these are examples of many topics discussed in the light of the most modern researches.

The chapters in this volume treat of external and internal structure, development and classification, and, out of the nine orders proposed, of the Aptera, Orthoptera, Neuroptera, and part of the Hymenoptera (Sessiliventres and Parasitica). The remaining orders will occupy vol. vi. of the series.

Of the chapter on development the most suggestive part is that on metamorphosis. Dr. Sharp urges that this phenomenon is yet very imperfectly understood, owing to our ignorance of the underlying physiological changes, and that nothing can be postulated about it without taking into account the processes of embryonic development and of such deviations from the normal course as hypermetamorphosis and the extraordinary changes undergone, for example, by parasitic Hymenoptera. The view that ecdysis is correlated solely with growth, is rejected in favour of Eisig's suggestion that it is a means of excretion.

NO. I 37 I, YOL. 537
It follows that metamorphosis is here regarded as of subordinate importance in classification, and though the usual definitions of its extent are rejected, no alternative scheme on a physiological basis is proposed. It is quite unlikely that entomologists will adopt the author's extreme views, but these pages, the result of much thought, will come as a surprise to those who have a comfortable belief in the fixity of the accepted degrees of metamorphosis, degrees which, as Camerano has said, are purely scholastic.

Sexual phenomena, such as heterogamy or dimorphism, are treated only in connection with the forms which exhibit them, but at the end of the chapter on internal anatomy there is a short paragraph on parthenogenesis and pædogenesis. It is nowhere indicated that the latter is an extreme form of the more general phenomenon of neotenia, alluded to under the Termitida.

Little importance is attached to the threadbare question of the division of the class into orders, and in the arrangement here adopted for convenience and without discussion the undue complexity of some recent systems has been, we think, wisely abandoned. Nine orders are indicated: the Neuroptera include the Pseudoneuroptera and Mallophaga, and two small orders only are kept separate, the Aptera (for Thysanura and

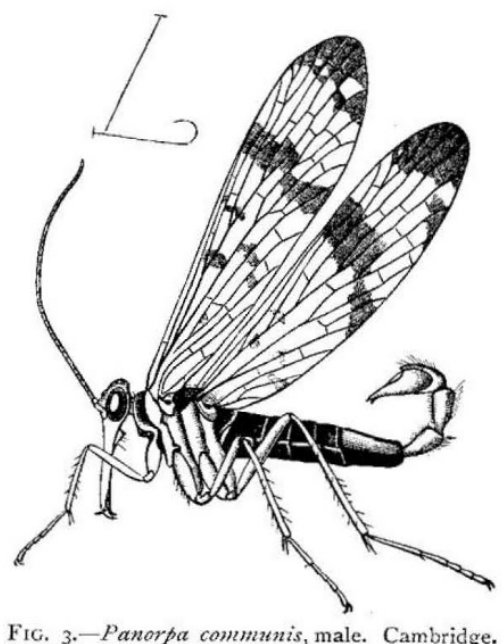

Collembola) and the Thysanoptera. The extension of Neuroptera to its original limits is in accordance with the views of some recent writers, for example, Brongniart. But with respect to the Aptera, which is coterminous with Brauer's Apterygogenea, attention has not been paid to Grassi's recent admission that the Thysanura, in common with all existing insects, may be derived from winged forms. They present many primitive features, but these are compatible with their place as the lowest Orthoptera, the homology of the abdominal styles with the legs having been lately seriously questioned. Though the inclusion of the Mallophaga in Neuroptera is not new, it is a pity that no. reasons are given for an association which, however sound, is hard to appreciate.

Of the variety of subjects in the chapters on the separate orders, we have already spoken. The Hymenoptera, being more homogeneous, are treated in somewhat less detail than the others. A figure of some of the manifold forms assumed by the petiolate abdomen would have been welcome, and among structural points there is no reference to the strange nipper-like front tarsi of Gonatopus.

In the chapter on Acridiida, no mention is made of the fact, important in connection with the migratory 
instinct, that the permanent homes of locusts are situate in sterile land, and it would have been well to remove the common misconception that the winged swarms are the chief enemies of the agriculturist; it is against the march of the larya, here graphically described in the words of an eyc-witness, that he has specially to guard.

There are a few inaccuracies and examples of loose expression, of which one or two may be mentioned. The author states that "the anterior portion of the intestine is the smaller, and is frequently spoken of as the colon," whercas clsewhore he alludes specifically to the ileum, which is often distinguishable. Certain glands in connecfion witl the uterus are twice called the "serific," once the "sebitic" glands; which term is meant is not clear. He adapts the term "instar" from Fischer to denote the form of an insect during a "stadium," that is, between consecutive colyses, but elsewhere he speaks not quite consistently of different instars as connoting a change of form, as well as of stadium. The reference to Chatin's views on the morphology of the mandible, would lead one to suppose that Chatin had found articulated mandibles in Embia. This is not the case; Chatin mercly compared the parts of the mandibulate mass with the jusints of the maxilla, and did so for many mandibulate insects and not Embia alone.

The standard which this work sets, if followed throughout the scrics, will leave the "Cambridge Natural History" without a rivil. The brok is me to be read not merely by entomologists, whose work it will certainly influence, but by general zoologists. The attention paid to insects in zoological teaching is quite dispro. portionate to the place they occupy in the animal kingdom ; but hitherto zoolngists have lad no guido to what is best worth knowing on the subject.

The volume presents all the beauty and finish which mark its precursor in the series. The illustrations, original or from original papers, are admirable; some of these: we are permitted to reproduce. Fig. I20 has been drawn in an inverted position and is not yuite clear, and a much better figure of Cylindrodes than the one given, accompanies (iray's original account of the genus. W. F. H. BLANDFORD.

\section{MEDICAI APPITATIONS OF RÖNTGEN'S} DISCOVERY.

THE

$\mathrm{HE}$ new photography has received the official recogvition which is usually given to scientific discovery in Germany. Prof. Röntgen las been honoured by the Emperor, and the I'russian Minister of War has caused experiments to be made in order to discover whether the mothod can be applied successfully to army surgcry. A scrics of photographs of bone injurics have shown so learly the nature of the wounds and the position of imbedded projectiles that it has been determined to carry on the experiments on a larger scale.

Medical science seems likely to benefit much by the application of Prof. Röntgen's discovery. The Rritis/t Mellical Joumal thinks, as an aid to diagnosis of obscure fractures and internal lesions generally, the new photography will be of great value. From our contemporary wc note that already a beginning has been made in this direction, and Prof. Mosctig, of Vicnua, has taken photographs which showed with the greatest clearness and precision the injuries caused by a revolver-shor in the lert hand of a man, and the position of the small projectile. In another case the same obscrver detected the prosition and nature of a malformation in the left foot of a girl with entire success. Prof. Lannelongue, of Paris, has also been successful in photographing some of his cases in his ward at the Trousseau Hospital, and, assisted by M.M. Qudin and Tarthelemy, has submitted to the Academy of Siences several negatives of human limbs. One of them represented a diseased thigh-bonc. The ; dcstroyed central portions had been penetrated by the light, forming white blotches on the platc. Another phoiograph was that of a tuberculous affection of the bone in a child's hand. The disease had been diagnosed, but photography brought complete confirmation to the diagnosis.

The Berlin correspondent of the Lancet, reforing to the practical use being made of the discovery, says in one case a tinger which had sustained a compound fracture, and from which a sequestrum bad been removed, was photographed by the new process, and the regeneration of the bone was thereby made visible. In another case the position of a piece of glass embedded in the tissues was ascertained by the sane method. Similar reports $\mathrm{cmme}$ from other Universities, as, for instance, from Berne, where Prof. Kocher has photographed a necdle in a woman's hand; it had made: its way under the skin some time ago, and had not been found by any other means.

\section{A CONTRIBLTION TO THE NEI PITOTOGRAPHY.}

T : MEROUS pictures are now being taken by means of the ncw method. The acconpanying illustration, which we owe to the kindness of Prof. Nernst, and the original of which was made by him in the Physical-chemical Laboratory at Göltingen, represents a luman hand as

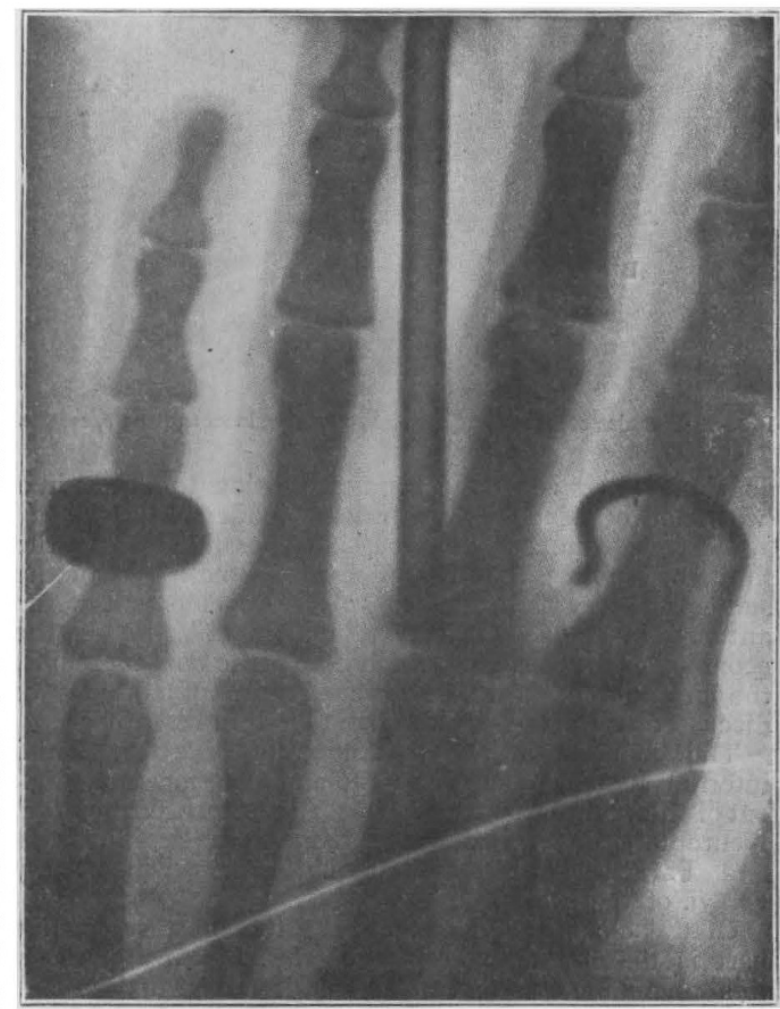

photographed by means of the Röntyen rays. It will be scen that the flesh is very nearly transparent for these rays, while the bones, the gold ring, the piece of wire, and the glass tube are practically opaque. The ring and wire, which were naturally in contact with the fiesh of the fingers, appear in the illustration as if suspended in the air
WIILIAM J. S. LOCKYER. 